PR

52,1

\section{2}

Received 17 February 2021

Revised 4 June 2021

7 August 2021

Accepted 14 September 2021

\title{
Designing innovative jobs: a fuzzy- set configurational analysis of job characteristics
}

\author{
Nicola Cangialosi \\ FORLILPSI, Università degli Studi di Firenze, Florence, Italy \\ Adalgisa Battistelli \\ EA4139 Laboratory of Psychology, University of Bordeaux, Bordeaux, France, and \\ Carlo Odoardi \\ FORLILPSI, Università degli Studi di Firenze, Florence, Italy
}

\begin{abstract}
Purpose - How to design jobs to support innovation is an issue that has received plenty of consideration over the past years. Building on the job characteristics model, the present study is set up to identify configurations of perceived job characteristics for innovation.

Design/methodology/approach - By adopting a fuzzy-set configurational approach (fsQCA), the research question is addressed through a two-wave self-report survey of 199 employees of an Italian manufacturing company.

Findings - Results reveal four compatible configurations of job characteristics leading to high levels of innovative work behavior and two for low levels.

Practical implications - The results offer guidance for managers and organizations that aim to strengthen employee-driven innovation by offering different recipes of job design to maximize the chance of boosting innovative behaviors among their workers.

Originality/value - This research is one of the first to empirically test the relation of job characteristics for innovative behavior using a configurational approach. By doing so it contributes to the literature by advancing the notion that innovative endeavors are determined by the holistic effects of different interdependent configurations of job characteristics.
\end{abstract}

Keywords Innovative work behavior, Job design, Job characteristics model

Paper type Research paper

\section{Introduction}

Over the past few decades, managers and researchers have been looking at ways to properly design jobs so that employees are more innovative (e.g. Hernaus, 2016). Employees can contribute to the development of innovations with their intentional generation, promotion and realization of new and useful ideas, processes, products or procedures within a role, group or organization (Janssen, 2000). These behaviors are defined as innovative work behaviors (IWB) and are a key factor in supporting the entire innovation process of public and private organizations (Potočnik and Anderson, 2016; Kmieciak, 2020; Battistelli et al., 2021).

Job design represents the content and structure of work tasks, activities, relationships and responsibilities and it's an important device for human resource management to strategically shape working practices (Parker, 2014). Job design specifically can be utilized to create a supportive and stimulating work environment that enhances IWBs (Parker et al., 2021).

(C) Nicola Cangialosi, Adalgisa Battistelli and Carlo Odoardi. Published by Emerald Publishing Limited. This article is published under the Creative Commons Attribution (CC BY 4.0) licence. Anyone may reproduce, distribute, translate and create derivative works of this article (for both commercial and noncommercial purposes), subject to full attribution to the original publication and authors. The full terms of this licence may be seen at http://creativecommons.org/licences/by/4.0/legalcode 
Numerous studies have pointed out that specific job designs can have either direct or indirect effects on individual innovation and related constructs (e.g. Parker and Ohly, 2008). One of the most influential theoretical foundations for designing jobs with increased innovative properties is the job characteristics model (JCM) (Hackman and Oldham, 1975). The JCM describes five core job characteristics, autonomy, skill variety, task significance, task identity and feedback. Past research has contributed to assessing the importance of this model for innovative behaviors in two separate manners.

The first analyzed the overall effect of job characteristics by aggregating them into a single construct, often referred to as job complexity. Job complexity has been found to contribute to innovation by stimulating, enhancing perceptions of challenge, and boosting intrinsic motivation (e.g. Audenaert et al., 2017). Employees performing complex tasks develop higher levels of responsibility for solving problems and therefore are more proactive, which leads them to generate and implement more and better ideas (Frese et al., 2007). Moreover, the execution of complex tasks facilitates the application of new knowledge, skills and abilities that are important for both the generation and implementation of new ideas (Amabile, 2012; Parker et al., 2021).

The second examined the association of job characteristics and innovation, considering the discrete effect of all characteristics separately. Several studies have connected each task characteristic with innovation highlighting significant associations with autonomy, variety of skills, task identity, job feedback and task significance (e.g. De Jong and Kemp, 2003).

Both directions have been investigated by research, resulting in a large body of evidence (Oldham and Fried, 2016). Nevertheless, while the first approach describes an overall effect of job complexity for innovation, not considering the specificity of each characteristic, the latter describes only the results of single characteristics, omitting the overall effect; therefore, much of the interaction of the underlying characteristics remains, to date, largely unexplored.

Prior theorizations suggested that combinations of job characteristics are more accurate predictors than single ones (Hackman and Oldham, 1975). All five job characteristics offer equally valuable work outcomes, but they do not show uniform effects, instead, they seem to interact with each other, combining in complex and synergic ways (Hernaus, 2016). Even if the theory rests on the assumption that these job attributes are compensatory (Meyer et al., 1993), so that a high level of one attribute counterweighs for a low level of others, no research has been done in this direction.

To specifically address this issue, the present study adopts a fuzzy-set (fsQCA) configurational approach (Farivar et al., 2019) to investigate combinations of causal conditions resulting from the interaction between job characteristics leading to high and low levels of innovative work behavior.

\section{Literature review}

\section{The job characteristics model}

The JCM is among the most prominent theories of job design. Hackman and Oldham's model (1975) defines five core job dimensions: autonomy, the degree to which employees have the freedom to decide how to perform their tasks; task significance, denoting how the job impacts other people's work, condition, or well-being; task identity, the extent to which a job requires performing distinguishable tasks from start to finish; skill variety, the amount of multiple high-level skills required to be utilized by employees on the job; and feedback, the degree to which employees are informed on how effective they are at work. These five core dimensions regulate three psychological states: skill variety, task identity and task significance shape "experienced meaningfulness"; autonomy affects "experienced responsibility", and feedback relates to "knowledge of results" (Hackman and Oldham, 1975). 
PR

52,1

\section{4}

In every job, all characteristics are present to a greater or lesser extent and the purpose of job design is to adjust the levels of each characteristic to facilitate any wanted outcomes (Oldham and Fried, 2016). The five job characteristics are not theoretically meant to be of equal value. Instead, Hackman and Oldham's original model (1975) proposed the following formula to calculate their effects, the motivating potential score (MPS), which later has been adopted as an aggregated measure of job complexity (Hackman and Oldham, 1975):

$$
\text { MPS }=\frac{(\text { Skill Variety }+ \text { Task Identity }+ \text { Task Significance })}{3} \times \text { Autonomy } \times \text { Feedback }
$$

This index depicts an a priori model of job characteristics represented by a three-way product of autonomy, feedback and the average of skill variety, task identity and task significance. A job must be perceived to be high on at least one of the three factors that lead to "experienced meaningfulness," and also must be high on both autonomy and feedback in order to lead to motivational outcomes. This, altogether, points to the notion that the components are all necessary, but none is sufficient for the determination of job design effects (Hinton and Biderman, 1995).

The five job characteristics are not meant to be assumed as objective features of a job, but rather individual perceptions, reflecting several cues and information deriving from the social surrounding (Talat and Riaz, 2020; Salancik and Pfeffer, 1978). This entails that different employees working on the same job may perceive their tasks differently in terms of skill variety, task identity, task significance, autonomy and feedback. Scholars have theoretically and methodologically explored this issue and examined whether employee self-ratings converged with evaluations made by other observers (e.g. Birnbaum et al., 1986). The results of research concerning the objectivity of employees' job ratings advise that, generally, employees deliver correct accounts of their job characteristics (Oldham and Fried, 2016). Consequently, most of the latest studies investigating job design adopts self-reports of employees' job characteristics (e.g. Astrauskaite et al., 2015).

Although the JCM core attempt was to provide guidance for designing jobs with augmented motivational properties (Hackman and Oldham, 1975), more recent conceptualizations have extended its conceptualization and broadened the field of study by linking it to other results (e.g. Grant et al., 2011). Numerous different outputs have been recognized by empirical studies over the years (Oldham and Fried, 2016). For example, research has examined the effects of jobs on employees' organizational citizenship behaviors (e.g. Zhang and Farndale, 2021), well-being (e.g. Daniels et al., 2017) and innovative-related constructs (Coelho and Augusto, 2010).

\section{Job design for innovation}

IWBs are context-dependent behaviors that can be affected by the nature of the work and by the different characteristics that it entails (Cerne et al., 2017; Cangialosi et al., 2021). Accordingly, job design can be understood as a key driving force for IWBs (e.g. Axtell et al., 2000) and several studies have recognized job characteristics as a major influence on employees' innovation (e.g. Afsar et al., 2019).

From a job complexity perspective, job characteristics are simplified as a single construct that has been related to IWB by several studies (e.g. Matthew et al., 2014). Oldham and Cummings (1996) found that the composite index of job characteristics (i.e. job complexity) was an effective predictor of individual innovation, as complex jobs compel employees to constant increase their knowledge, skills and abilities to keep up with the introduction of new technologies and procedures in the workplace (Oldham and Cummings, 1996). These jobs improve employees' enthusiasm and motivation for work thus stimulating their innovative behaviors (e.g. Ohly and Fritz, 2010). Research also indicates that job complexity is positively 
related to employees' synthesis of knowledge from various sources which also favors innovative results (Cangialosi et al., 2020a). Similarly, Shalley et al. (2009) found a direct effect of job complexity on an innovative-related construct, self-reported creative performance. Park et al. (2016) stated that openness to experience employees are more likely to undertake IWBs when perceiving their job to be complex in association with an innovative climate. More recently, Audenaert et al. (2017) suggested that the effects of psychological empowerment on individual innovation are contingent on the levels of perceived job complexity.

From a single characteristics approach, autonomy is by far the most studied in relation to innovative-related outcomes (Wang and Cheng, 2010). Employees with more autonomy in their jobs have more power and control over their tasks tend to be more flexible and innovative (Slatten and Mehmetoglu, 2011). Autonomous decision-making leads to higher levels of IWB, by intrinsically motivating and exerting more determination which translates into propensity and capacity to innovate (Zhang et al., 2020). From an opposite perspective, Luoh et al. (2014) found job standardization (i.e. lack of autonomy) to negatively affect employees' motivation and enthusiasm and reduce IWB. Job autonomy not only affects intrinsic motivation, but it also influences creative self-efficacy which is strongly correlated to individual innovation (Gupta, 2020). Furthermore, employees that are given more choice experience a sense of trust from the organization and are more confident in searching for new and useful approaches to problems and delivering innovative outcomes (Dorenbosch et al., 2005).

Task significance also has received some attention in association with innovation. Task significance is strongly related to the amount of intrinsic motivation employees show (Coelho and Augusto, 2010) which can result in innovative behaviors (Zhang and Bartol, 2010). Recently, Lee and Jeon (2020) highlighted that the effect of task significance on creative behavior. Additionally, Yang and Cho (2015) revealed a direct effect of task significance on IWB and Cangialosi et al. (2020b) found that task significance increased the effects of learning on IWB in presence of high levels of autonomy.

Moreover, task identity was found significantly related to IWB (Coelho and Augusto, 2010). Task identity provides meaningfulness and increases the intrinsic motivation of employees and consequently their willingness to innovate (Hartmann, 2006). Yet, a study of Deegahawature (2014) concluded the opposite, suggesting that jobs as an entire piece may be a constraint for innovation.

Another key job characteristic for IWB is skill variety (Li and Hsu, 2016). Employees adopting multiple skills in their job tasks demonstrate more innovative behaviors (Chang et al., 2011). Skill variety drives employees to develop various skills and this further fosters the generation and realization of new ideas (Chen et al., 2011). Moreover, employees' learning enhanced by skill variety is related to creative self-efficacy which in turn revolves in higher levels of IWB (Gong et al., 2009).

Finally, job feedback has been found to enhance employees' knowledge acquisition, personal growth and satisfaction of job tasks thus individual innovation (Coelho and Augusto, 2010). Yang and Cho (2015) found that feedback from the job was directly associated with IWB and Ahn and Hong (2011) that feedback had positive relationships with incremental innovation. Furthermore, a study by Battistelli et al. (2013) established that job feedback would increase the relationship between short-term thinking, and emotional reaction and innovative performance, such that a positive and significant association emerged only in the case of high feedback.

\section{Research question}

The importance of job characteristics to IWB has been largely recognized both combined as an index and singularly as discrete characteristics (e.g. Parker et al., 2017). However, several conceptual works have stated the necessity to move beyond this duality of approaches to a 
PR

52,1

\section{6}

more holistic perspective. For instance, De Treville and Antonakis (2006) suggested that a configuration of job characteristics would be more important for employees' intrinsic motivation than independent main effects. Moreover, several recommendations have been made for methodological improvements, such as to consider how distinctive configurations of work characteristics might create synergistic effects (e.g. Parker et al., 2017). Additionally, Lee and Raschke (2016) more directly, advocated for the use of set-theoretic methods, such as fuzzy set qualitative comparative analysis (fsQCA), to address the effects of job design. All of these suggestions together hint at the configurational approach to be a logical extension of the JCM (Meyer et al., 1993).

Previous studies did not account for the reciprocal interdependence between job characteristics, and chiefly applied symmetric approaches of analysis grounded on the "neteffects" assumption (e.g. SEM). Yet, such methods do not comprise co-occurring causality among independent variables to explain a result (Woodside, 2014). Consequently, the adoption of those techniques inhibits the possibility to capture complex interdependencies, mutual causality between predictors, and nonlinearities that characterize behaviors inside organizational settings (Meuer and Fiss, 2020; Greckhamer et al., 2018).

Conversely, fsQCA is a more appropriate method to assess such complexity (Dahms and Kingkaew, 2019; Farviar et al., 2019; Lo et al., 2019) as it allows a behavior (IWB) to be regarded as clusters of interconnected causal conditions (job characteristics) that are intended to be assessed as holistic combinations rather than independent conditions (Woodside, 2014). Based on the aforementioned arguments, the present study is articulated through a research question (Figure 1).

Research question. Which, if any, theoretically possible configurations of job characteristics are considered sufficient for high/low levels of innovative work behavior?

\section{Method}

\section{Data collection}

This study was conducted as part of a broader human resource management project designed to enhance employees' innovative behavior at work in a manufacturing company in central Italy. The organization was involved in its entirety including all departments (production, accounting, and management), and organizational levels (from first-line employees to top management). The study was based on data deriving from surveys made

Figure 1.

Conceptual model

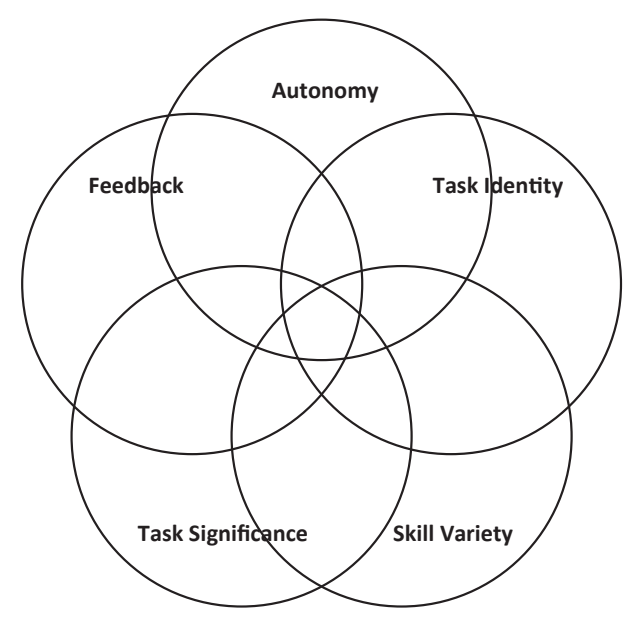

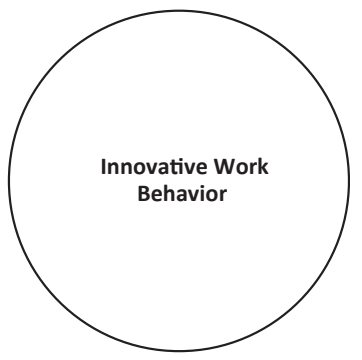


available in Italian to all employees. Two self-evaluation questionnaires were administered at two-point time, at a 6-month distance. Completion was rendered either on paper during work hours or online. Participation was on a voluntary basis and confidentiality was guaranteed. Participation of 232 (t1) and 199 (t2) employees was achieved, representing a return rate of $93 \%$, at $\mathrm{t} 1$, and $80 \%$, at $\mathrm{t} 2$, of the total population (247).

At $t 2$ the sample consisted of $73 \%$ males and $27 \%$ females. Most of the respondents were high school graduates $(66 \%$ ), about $13 \%$ had a master's degree or higher and $20 \%$ held a secondary school diploma. Additionally, almost $64 \%$ of the respondents were 35-45 years old. Finally, $16 \%$ of the participants were managers, $32 \%$ office workers, and the remaining $52 \%$ production employees.

\section{Measures}

All measures were drawn from internationally validated scales. Numerous studies have previously translated them following the back-translation procedures recommended by Brislin (1980) and adopted them to the Italian context (e.g. Cangialosi et al., 2020b).

Job characteristics. Autonomy, feedback, task identity, task significance and skill variety were assessed with the Morgeson and Humphrey's (2006) WDQ 3 items per dimension were selected for the purpose of this study. Examples of items are "my job allows me to decide the order in which my activities must be done" for autonomy, "the work activities themselves provide direct and clear information about the effectiveness (e.g. quality and quantity) of my job performance" for feedback, "The job provides me the chance to completely finish the pieces of work I begin" for task identity, "The results of my work are likely to significantly affect the lives of other people" for task significance and "my job involves performing a variety of different tasks" for skill variety. All items were measured using a five-point Likerttype scale from "strongly disagree" to "strongly agree."

Innovative work behavior. Innovative work behavior was measured with Janssen's (2000) nine-item scale. Examples of items are, how often in the past six months "I created new ideas to solve difficult problems" and "I introduced new ideas in the working environment in a systematic way." All items were measured using a five-point Likert-type scale from "very often" to "never."

\section{Preliminary analyses}

Reliability and validity were assessed for the constructs of this study. Cronbach's alpha and McDonald's omega of all factors were found above the advised thresholds, indicating acceptable levels of internal consistency, IWB $(\alpha=0.92 ; \omega=0.92)$; autonomy $(\alpha=0.74$; $\omega=0.76)$; feedback $(\alpha=0.85 ; \omega=0.85)$; task identity $(\alpha=0.76 ; \omega=0.72)$; task significance $(\alpha=0.74 ; \omega=0.76)$; skill variety $(\alpha=0.84 ; \omega=0.83)$.

The average variance extracted (AVE) was measured to establish discriminant validity, resulting in greater than 0.50 , ranging between 0.53 and 0.63 . Additionally, the correlations between the different variables did not exceed 0.80 and the square root of each factor's AVE was tested against its correlations with other factors and shown to be higher (Fornell and Larcker, 1981). The findings are presented in Table 1.

Additionally, common latent factor technique and Harman's single-factor test were assessed to check for multicollinearity along with the eventual risk of common method bias (Podsakoff et al., 2012). Each construct variance inflation factor was lower than 3, showing that multicollinearity was not a concern. Also, no single factor explained more than $33.36 \%$ of the total variance between constructs, suggesting that common method bias was not present.

\section{FsQCA}

Due to the skewness of the study constructs (common in large- $N$ settings), the calibration procedure was performed using percentiles to avoid producing less significant outcomes 
PR

52,1

\section{8}

Table 1.

Descriptive statistics and correlations
(Pappas et al., 2017). Based on the results of the probability density function and on Beynon et al.'s procedure (2016), the three qualitative anchors were selected for each construct full-set inclusion (95th percentile), crossover point (50th percentile) and exclusion (5th percentile). Scores were subsequently transformed into set measures based on the qualitative anchors (Ragin, 2008). The calibrated scores were bound to the thresholds of full membership, the crossover point, and full non-membership (fuzzy score $=0.95,0.50,0.05$; respectively).

Then, with the current version of the fsQCA software (Ragin, 2006) a truth table of $2 \mathrm{k}$ rows was produced (Table 2), with $k$ representing the number of outcome predictors and rows all possible combinations. The truth table was sorted based on frequency and consistency (Ragin, 2008). Consistency for sufficient solutions was set at $\geq 0.80$ (Ragin, 2008) and frequency at two cases per configuration, following the guidelines for samples with large number of cases (199). Additionally, to lessen the chance of paradoxical results, a PRI (proportional reduction in inconsistency) measure of consistency cut-off was set at $\geq 0.50$, as configurations with lower PRI indicate significant inconsistency (Greckhamer et al., 2018). Nonetheless, more than $80 \%$ of total cases was retained in the truth table.

FsQCA offers three methods for dealing with logical remainders: complex, parsimonious and intermediate solutions (Schneider and Wagemann, 2010). The difference between each solution lies in the simplifying assumptions about the supposed result of the configurations showing no corresponding cases. The intermediate solution was selected because logical remainders can be limited to those that are deemed most reasonable (Ragin, 2008). Results were subsequently confronted with the parsimonious solution to set core and peripheral conditions (Fiss, 2011).

\section{Findings}

Prior to the fuzzy-set truth table process, necessity analysis was carried out to assess whether any singular condition was necessary for the outcome to occur (Table 3). However, no contextual condition exceeded the threshold of 0.90 consistency score for high nor for low levels of IWB (Schneider and Wagemann, 2010).

\section{Results for high levels of innovative work behavior}

The results of the fuzzy-set analysis for sufficient conditions showed that the intermediate solution contained four configurations with an acceptable overall solution consistency of 0.83 , surpassing the suggested threshold of 0.75 . This indicates that the causal conditions are sufficient for the outcome (Table 4). The overall solution coverage is approximately $37 \%$ of the total membership in IWB, which is between 20 and 65\% recommendation (Woodside, 2014; Dahms and Kingkaew, 2019). The unique contribution of causal conditions to high IWB in each configuration is significant, being higher than zero (Schneider and Wagemann, 2010).

\begin{tabular}{|c|c|c|c|c|c|c|c|c|c|}
\hline Construct & $M$ & $\mathrm{SD}$ & AVE & 1 & 2 & 3 & 4 & 5 & 6 \\
\hline 1. IWB & 2.63 & 0.83 & 0.61 & 0.78 & & & & & \\
\hline 2. Autonomy & 3.17 & 0.85 & 0.54 & 0.42 & 0.73 & & & & \\
\hline 3. Feedback & 3.14 & 0.91 & 0.63 & 0.27 & 0.32 & 0.79 & & & \\
\hline 4. Task identity & 3.33 & 0.78 & 0.53 & 0.28 & 0.38 & 0.45 & 0.71 & & \\
\hline 5. Task significance & 3.59 & 0.82 & 0.66 & 0.26 & 0.32 & 0.55 & 0.27 & 0.61 & \\
\hline 6. Skill variety & 3.53 & 0.83 & 0.62 & 0.37 & 0.42 & 0.32 & 0.20 & 0.47 & 0.78 \\
\hline
\end{tabular}

Note(s): Square roots of the AVE are presented in italic as diagonal elements. Off-diagonal elements are the correlations among constructs ( 0.2 or higher are significant, $p<0.01$ ) 


\begin{tabular}{|c|c|c|c|c|c|c|c|c|c|}
\hline AUT & FEED & $\mathrm{TI}$ & TS & SV & No. of cases & Perc. of sample & Raw cons & PRI cons & Designing \\
\hline 0 & 0 & 0 & 0 & 0 & 28 & 14.07 & 0.54 & 0.36 & \\
\hline 1 & 1 & 1 & 1 & 1 & 23 & 11.56 & 0.86 & 0.83 & \\
\hline 0 & 0 & 1 & 0 & 0 & 15 & 7.54 & 0.50 & 0.28 & \\
\hline 1 & 0 & 0 & 0 & 0 & 11 & 5.53 & 0.64 & 0.32 & \\
\hline 1 & 1 & 1 & 1 & 0 & 11 & 5.53 & 0.67 & 0.46 & \\
\hline 0 & 1 & 1 & 0 & 0 & 10 & 5.03 & 0.51 & 0.34 & 389 \\
\hline 1 & 0 & 1 & 0 & 0 & 9 & 4.52 & 0.67 & 0.41 & \\
\hline 1 & 1 & 1 & 0 & 0 & 8 & 4.02 & 0.71 & 0.48 & \\
\hline 0 & 1 & 1 & 1 & 1 & 8 & 4.02 & 0.67 & 0.57 & \\
\hline 0 & 0 & 0 & 0 & 1 & 7 & 3.52 & 0.70 & 0.50 & \\
\hline 0 & 0 & 0 & 1 & 0 & 6 & 3.02 & 0.64 & 0.44 & \\
\hline 0 & 1 & 0 & 0 & 0 & 5 & 2.51 & 0.62 & 0.37 & \\
\hline 1 & 0 & 0 & 1 & 0 & 5 & 2.51 & 0.71 & 0.51 & \\
\hline 0 & 1 & 1 & 1 & 0 & 5 & 2.51 & 0.56 & 0.35 & \\
\hline 1 & 0 & 1 & 0 & 1 & 5 & 2.51 & 0.74 & 0.62 & \\
\hline 1 & 0 & 1 & 1 & 0 & 4 & 2.01 & 0.80 & 0.56 & \\
\hline 0 & 1 & 1 & 0 & 1 & 4 & 2.01 & 0.82 & 0.76 & \\
\hline 1 & 1 & 1 & 0 & 1 & 4 & 2.01 & 0.86 & 0.79 & \\
\hline 1 & 0 & 0 & 1 & 1 & 4 & 2.01 & 0.70 & 0.50 & \\
\hline 1 & 1 & 0 & 1 & 1 & 4 & 2.01 & 0.67 & 0.52 & \\
\hline 1 & 0 & 1 & 1 & 1 & 4 & 2.01 & 0.86 & 0.77 & \\
\hline 1 & 1 & 0 & 1 & 0 & 3 & 1.51 & 0.67 & 0.47 & \\
\hline 1 & 1 & 0 & 0 & 0 & 2 & 1.01 & 0.62 & 0.32 & \\
\hline 0 & 1 & 0 & 1 & 0 & 2 & 1.01 & 0.67 & 0.50 & \\
\hline 1 & 0 & 0 & 0 & 1 & 2 & 1.01 & 0.79 & 0.58 & \\
\hline 0 & 0 & 1 & 0 & 1 & 2 & 1.01 & 0.66 & 0.50 & \\
\hline 0 & 0 & 0 & 1 & 1 & 2 & 1.01 & 0.67 & 0.43 & \\
\hline 0 & 1 & 0 & 1 & 1 & 2 & 1.01 & 0.75 & 0.61 & \\
\hline 0 & 0 & 1 & 1 & 0 & 1 & 0.50 & 0.63 & 0.35 & \\
\hline 0 & 1 & 0 & 0 & 1 & 1 & 0.50 & 0.76 & 0.56 & \\
\hline 1 & 1 & 0 & 0 & 1 & 1 & 0.50 & 0.85 & 0.72 & QCA truth table for the \\
\hline 0 & 0 & 1 & 1 & 1 & 1 & 0.50 & 0.74 & 0.56 & $\begin{array}{l}\text { outcome innovative } \\
\text { out }\end{array}$ \\
\hline \multicolumn{10}{|c|}{ Note(s): AUT: autonomy; FEED: feedback; TI: task identity; TS: task significance; SV: skill variety $\quad$ work behavior } \\
\hline
\end{tabular}

All configurations are acceptable subsets of high IWB as consistency is beyond the suggested threshold of 0.75 (Woodside, 2014). Finally, the raw coverage scores for solutions $\mathrm{a} 1$ and $\mathrm{a} 2$ are relatively high and imply greater empirical importance than a 3 and $\mathrm{a} 4$. The results of fsQCA for high levels of IWB are shown in Table 4.

Configuration a1 suggests that high levels of autonomy, task identity, skill variety and feedback may lead to high levels of IWB regardless of their level of task significance. Configuration a 2 posits that high levels of autonomy, task identity, skill variety and task significance, may lead to high levels of IWB regardless of feedback. Configuration a3 suggests that at low levels of task significance the simultaneous presence of, skill variety, feedback and task identity, the latter as peripheral condition, may lead to high levels of IWB regardless of job autonomy. Finally, configuration a4 posits that the conjoint presence of high levels of task significance, task identity and autonomy, the last being peripheral condition, regardless of skill variety, may lead to high levels of IWB when feedback is low.

Results for low levels of innovative work behavior

Table 4 shows two substitutable configurations with acceptable overall solution consistency $(\geq 0.75)$ and coverage above the recommended $20 \%$ of the total membership in the outcome 


\begin{tabular}{|c|c|c|c|c|c|}
\hline \multirow{3}{*}{$\begin{array}{l}\text { PR } \\
52,1\end{array}$} & \multirow[b]{3}{*}{ Attribute } & \multirow{2}{*}{\multicolumn{2}{|c|}{ Outcome: IWB }} & & \\
\hline & & & & \multicolumn{2}{|c|}{ Outcome: IWB } \\
\hline & & Consistency & Coverage & Consistency & Coverage \\
\hline \multirow[b]{5}{*}{390} & Autonomy & 0.579 & 0.637 & 0.422 & 0.453 \\
\hline & $\sim$ Autonomy & 0.502 & 0.471 & 0.661 & 0.605 \\
\hline & Task significance & 0.621 & 0.613 & 0.472 & 0.454 \\
\hline & Task significance & 0.447 & 0.464 & 0.598 & 0.606 \\
\hline & Task identity & 0.559 & 0.616 & 0.438 & 0.471 \\
\hline \multirow{6}{*}{$\begin{array}{l}\text { Table } 3 \text {. } \\
\text { Necessary analyses for } \\
\text { the occurrence (and no } \\
\text { occurrence) of IWB }\end{array}$} & Task identity & 0.521 & 0.487 & 0.643 & 0.587 \\
\hline & Skill variety & 0.634 & 0.665 & 0.421 & 0.431 \\
\hline & $\sim$ Skill variety & 0.458 & 0.447 & 0.673 & 0.642 \\
\hline & Feedback & 0.648 & 0.604 & 0.532 & 0.484 \\
\hline & $\sim$ Feedback & 0.446 & 0.495 & 0.564 & 0.610 \\
\hline & \multicolumn{5}{|c|}{ Note(s): Indicates a logical NOT (the absence of a condition) } \\
\hline
\end{tabular}

Table 4.

Combinations to innovative work behavior

\begin{tabular}{lcccccc}
\hline & & \multicolumn{2}{c}{ IWB } & \multicolumn{2}{c}{ Lack of IWB } \\
Conditions & $\mathrm{a} 1$ & $\mathrm{a} 2$ & $\mathrm{a} 3$ & $\mathrm{a} 4$ & $\mathrm{~b} 1$ & $\mathrm{~b} 2$ \\
\hline Autonomy & $\bullet$ & $\bullet$ & & $\bullet$ & $\bullet$ & $\varnothing$ \\
Task significance & & $\bullet$ & $\varnothing$ & $\bullet$ & $\emptyset$ & $\emptyset$ \\
Task identity & $\bullet$ & $\bullet$ & $\bullet$ & $\bullet$ & $\varnothing$ & $\emptyset$ \\
Skill variety & $\bullet$ & $\bullet$ & $\bullet$ & & $\varnothing$ & $\emptyset$ \\
Feedback & 0.862 & 0.863 & 0.797 & 0.831 & 0.814 & 0.807 \\
Consistency & 0.295 & 0.289 & 0.115 & 0.102 & 0.160 & 0.116 \\
Raw coverage & 0.008 & 0.006 & 0.021 & 0.015 & 0.081 & 0.074 \\
Unique coverage & 0.835 & & & & 0.809 & \\
Solution consistency & 0.369 & & & & 0.235 & \\
Solution coverage & & & &
\end{tabular}

Note(s): Black circles (“๑”) indicate high condition, cross circles ("Ø”) low condition and blank spaces "do not care" condition; large circles denote core conditions, while small circles indicate peripheral conditions

(Woodside, 2014). The unique contribution is significant as it is above zero (Schneider and Wagemann, 2010). The two configurations are satisfactory subsets of low IWB as their consistencies exceed the recommended threshold of 0.75 (Woodside, 2014).

The first configuration, b1, shows that high levels of autonomy and the simultaneous low levels of all the other characteristics, with skill variety as peripheral condition, regardless of the level of feedback, may lead people to low levels of IWB. Additionally, configuration b2 suggests that high levels of task identity may lead people to low levels of IWB when all the other characteristics are at low levels, with task significance and skill variety as a peripheral condition.

Predictive validity, robustness and sensitivity analyses

The present study tested for predictive validity to identify the model capacity to generate the same outcome on different samples (Pappas et al., 2017). The procedure followed involved, first dividing the sample in two, subsample and holdout sample, then carrying out sufficiency analysis for the subsample, and subsequently testing the results against the holdout sample. Table 5 illustrates patterns of complex conditions as consistent indicators of high levels of IWB for the subsample (overall solution consistency $=0.83$ ).

All of the four configurations presented in Table 5 are models to be plotted against the result. This requires that each configuration is merged in a single construct in fsQCA, and, 
once the new constructs are created, they are then plotted with IWB as the outcome. Figure 2 shows the results for testing model 1 on the holdout sample. These indicate parallel results to those from the subsample (Table 5), with that adequate levels of consistency $(0.85)$ and coverage (0.35). From the predictive tests carried out on all the models, it is possible to assume that the configurations displaying high consistency for the subsample have a high predictivity for the holdout sample and vice versa.

Finally, to check the robustness and sensitivity of analyses, the fsQCA procedure was repeated with multiple altered methods. According to Skaaning (2011), the types of robustness checks for fsQCA results must include changes in calibration thresholds and in the consistency of configurations. Accordingly, first, the calibration approach was changed using the procedure employed by Ordanini et al. (2014) where the three qualitative anchors are based on the survey scale (five-point Likert). The full membership threshold was fixed at

\section{Designing innovative jobs}

391

\begin{tabular}{|c|c|c|c|}
\hline Models from subsample 1 & Raw coverage & Unique coverage & Consistency \\
\hline AUT*TI*SV & 0.291 & 0.167 & 0.849 \\
\hline AUT* ${ }^{*}$ TS $*$ TI & 0.132 & 0.023 & 0.793 \\
\hline$\sim \mathrm{TS} * \mathrm{TI} * \mathrm{FEED} * \mathrm{SV}$ & 0.134 & 0.034 & 0.912 \\
\hline$\sim \mathrm{AUT}^{*} \sim \mathrm{TS}^{*} \sim \mathrm{TI}^{*} \mathrm{FEED}^{*} \sim \mathrm{SV}$ & 0.091 & 0.039 & 0.808 \\
\hline$\sim \mathrm{AUT}^{*} \sim \mathrm{TS}^{*} \sim \mathrm{TI}^{*} \sim \mathrm{FEED}{ }^{*} \mathrm{SV}$ & 0.124 & 0.056 & 0.828 \\
\hline$\sim \mathrm{AUT} * \mathrm{TS} * \sim \mathrm{TI} * \mathrm{FEED} * \mathrm{SV}$ & 0.114 & 0.61 & 0.803 \\
\hline Overall solution consistency & 0.825 & & \\
\hline Overall solution coverage & 0.539 & & \\
\hline
\end{tabular}

Note(s): AUT: autonomy; FEED: feedback; TI: task identity; TS: task significance; SV: skill variety
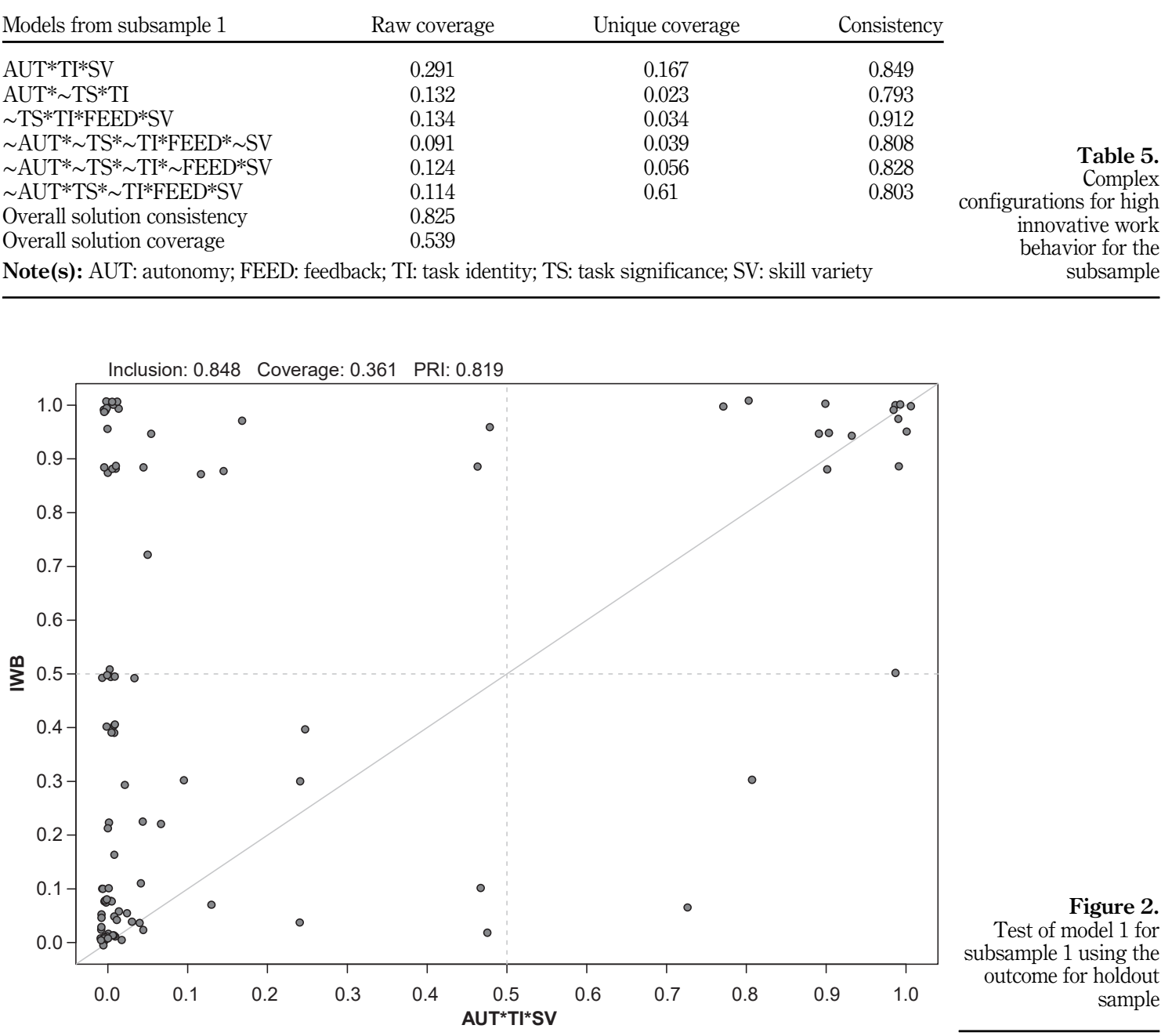

Figure 2.

Test of model 1 for subsample 1 using the outcome for holdout sample 
PR

52,1

392

4; the full non-membership threshold at 2 ; and the crossover point at 3 . The new anchors were then adopted to calibrate all the conditions while keeping the same frequency threshold of 2 and consistency threshold of 0.80 . The results for the sufficiency test did not highlight any major discrepancies from the prior.

Then, following Ragin's recommendation (2008) to compare sufficiency test results with a more restrictive consistency threshold, analyses were repeated setting the consistency threshold to 0.85 while maintaining the numerosity of 2 . However, when increasing the consistency threshold, only minor changes were observed in the number of solutions and the overall reading of the results stayed unaffected.

\section{Discussion}

The present study takes a diverse approach from traditional innovation and job design research employing configurational analysis. By considering the role of different configurations of job characteristics, this paper aimed at shedding light on how distinct job recipes may lead employees to high levels of innovative work behaviors. To this end, the research question based upon the JCM (Hackman and Oldham, 1975) served as the basis for identifying and discussing configurations of job characteristics for enhancing individual innovation. First, necessity analysis underlined that no single necessary condition was present for high levels of innovative work behavior nor low levels. Second, sufficiency analysis exposed and explored four configurations leading to high levels of innovative work behavior and two leading to low levels (Research Question).

Configuration a1 and 2 represent two permutations of a profile that consistently lead to high levels of IWB. They share three core conditions (autonomy, task identity, and skill variety) and only differ on the presence of high levels of task significance and feedback. A1 displays high levels of feedback, regardless of those of task significance and a2 high levels of task significance regardless of those of feedback. These results point at a substitution effect in which feedback and task significance do not coexist when employees experience high levels of the remaining job characteristics. Consequently, these solutions suggest that it is sufficient to design jobs entailing high levels of autonomy, task identity and skill variety with the presence of either high feedback or high task significance to facilitate employees' innovation. This result seems to back the original theorization of the JCM as per obtain high levels of IWB job characteristics must be high on most of the job characteristics.

Interestingly, configuration a3 and a4 display a similar effect, where low levels of task significance and feedback do not co-occur. Configuration a3 suggests that when task significance is low it is sufficient for employees' innovation to experience high levels of task identity skill variety and feedback regardless of the level of autonomy. Configuration a4 implies that when feedback is low high levels of autonomy, task significance and task identity are sufficient to promote individual innovation regardless of skill variety. Taken together these findings highlight a specific effect of substitution between feedback and task significance. This result could be read in light of the cognitive load theory which has been previously shown to be affected by task characteristics (Paas and van Merriënboer, 2020). When, together with the other job characteristics, both task significance and feedback are high so is the employees' cognitive load, accordingly mental resources are likely unavailable for additional cognitive activities. In sum, when employees are occupied in processing many elements, there may be little opportunity for generating and implementing new and useful ideas (i.e. IWB). This is new to the literature and allows a deeper understanding of the interplay of job characteristics and highlights more complex synergies than previously theoretically hypothesized (Hackman and Oldham, 1975).

Additionally, the role of task identity is of particular interest as it is present in all out of the four configurations for high IWB. This advises a stronger relation with innovation than prior 
studies assumed (e.g. Humphrey et al., 2007). Also, past research has been inconsistent regarding the role of task identity for innovation. Some authors found task identity to be positively associated with individual innovation, as it increases job meaningfulness and intrinsic motivation of employees (Coelho and Augusto, 2010), while others finding contrary results, reached the opposite conclusion, proposing that jobs as an entire piece may constraint individual innovative efforts (Deegahawature, 2014). The present results back to the first standpoint, as task identity is a condition present in all the sufficient configurations for high levels of IWB.

Concerning low innovative work behavior, two configurations have been indicated by sufficiency analysis. The first requires high levels of autonomy when all other characteristics are below average regardless of the levels of feedback (b1), the latter high levels of task identity, when all other conditions are low (b2). This adds to the literature as little is known about what factors lead to low levels of IWB. Besides, the presence of high levels of autonomy (b1) and task identity (b2) in sufficient configurations is somewhat unexpected and should be further analyzed.

Moreover, according to this MPS formula, autonomy and feedback are assumed to be three times more significant compared to skill variety, task identity, or task significance. This translates to the conception that if a job is high in autonomy (or feedback), regardless of levels of variety, identity, and significance, its behavioral effects will be very high. The present results point in the same direction, as in every sufficient configuration either high levels of autonomy or feedback are present. However, the findings offer more nuanced details about this interaction. In fact, in a3 configuration autonomy is in condition of "do not care," signifying that regardless of the level of perceived autonomy, employees can reach high levels of innovative work behavior when conditions of high task identity, skill variety and feedback are present, together with low levels of task significance. Additionally, in a4 configuration high levels of innovative work behavior can be obtained even at low levels of feedback when task identity, task significance and autonomy are present. This suggests stronger importance of the job characteristics underlining the experienced meaningfulness psychological state than theoretically assumed.

In summary, these results are of interest as they signify the importance of intending job design in a more rounded and holistic manner, as even at high levels of a single characteristic may lead to low results when the other characteristics are below average. The fsQCA results revealed details about the heterogeneity of effects of job design, identifying different configurations leading to high and low levels of individual innovation. The presented outcomes facilitated the effort to unpack heterogeneity of job design resulting in a grouping of job characteristics that is more fine-grained than the dichotomy of single characteristics vs the aggregated job complexity.

\section{Implications}

Even if the importance of job characteristics to IWB has been largely acknowledged both combined, as an index, and singularly, as discrete characteristics, managers are still designing simple and monotonous jobs (Ohly and Fritz, 2010). Yet, such jobs do not favor employees' innovation, because they fail to motivate and challenge the employees (Axtell et al., 2000). To design jobs aimed at maximizing individual innovation, managers are required to strike a balance among job characteristics for stimulating IWB (Whittington et al., 2004). To this extent, the present study makes new and important contributions to the literature on job design and innovation.

First, the present study is among the firsts to deliver a detailed analysis of the combined/ interactive role of job characteristics to promote employee-driven innovation. To date, studies on job design have considered each job characteristic separately or combined in a single 
construct (i.e. job complexity) rather than interactively. Employing fsQCA to answers the call for a combined/interactive approach (e.g. Parker et al., 2017) seems to hold considerable potential as it helps closing an important gap in the job design literature. Second, presented results hold considerable promise to overcome the abovementioned mismatch between theory and methods and to enable detailed analyses of combinations of causal conditions resulting in low and high IWB.

From a practical perspective, the present findings provide useful insights that may help organizations understand how jobs should be designed to promote high levels of innovation. HR policies, focusing on increasing the innovative behavior of employees should first and foremost focus on enhancing the employees' job characteristics, presented results show that specific configurations are more likely to drive individual innovation than others. Extending prior research, these findings suggest that focusing on isolated job characteristics to promote innovation has a minor value. Instead, if organizations want to promote IWBs, they should design balancing job characteristics matching the presented configurations.

\section{Limitations and future research}

Although this study makes several significant contributions, it has some limitations that need to be carefully addressed in future research. First, all data were collected with selfreporting measures, this was done because, for both innovative work behavior and job characteristics, the use of supervisor reports may not necessarily be appropriate. Employees have more direct information about the specificity of job tasks as well as the extent to which they have generated, proposed and realized their ideas in the organization (Janssen, 2000). Nevertheless, using self-report measures may lead to the common method bias in observed relationships. However, this study adopted the statistical recommendations of Podsakoff et al. (2012) for dealing with common method errors.

Second, the present study concentrated on the core five job characteristics which assess how work is accomplished and the range and nature of job tasks. However, there is theoretical ground to assume that also other job-related features should be considered as important conditions for IWB. For this reason, future studies should aim at also including knowledge characteristics, regarding the kinds of knowledge, skill, and ability demands that are placed on the job (e.g. information processing), social characteristics, concerning the amount and quality of interaction with others on the job (e.g. interdependence), and contextual characteristics referring to the specific setting or physical environment of a job (e.g. ergonomics).

Finally, the sampling strategy focused on the study of a medium-sized manufacturing company from a single country. Future research should increase both the sample size and the number of organizations involved and should differentiate its geographical locations.

\section{References}

Afsar, B., Masood, M. and Umrani, W.A. (2019), "The role of job crafting and knowledge sharing on the effect of transformational leadership on innovative work behavior", Personnel Review, Vol. 48 No. 5, pp. 1186-1208, doi: 10.1108/PR-04-2018-0133.

Ahn, K.Y. and Hong, K.H. (2011), "The relationship between job characteristics and incremental innovation, and the moderating effect of tenure", Journal of the Korea Safety Management and Science, Vol. 13 No. 1, pp. 167-173, doi: 10.12812/ksms.2011.13.1.167.

Amabile, T.M. (2012), "Componential theory of creativity", Harvard Business School, Vol. 12 No. 96 , pp. 1-10.

Astrauskaite, M., Notelaers, G., Medisauskaite, A. and Kern, R.M. (2015), "Workplace harassment: deterring role of transformational leadership and core job characteristics", Scandinavian Journal of Management, Vol. 31 No. 1, pp. 121-135, doi: 10.1016/j.scaman.2014.06.001. 
Audenaert, M., Vanderstraeten, A. and Buyens, D. (2017), "When innovation requirements empower individual innovation: the role of job complexity", Personnel Review, Vol. 46 No. 3, pp. 608-623, doi: 10.1108/pr-10-2014-0219.

Axtell, C.M., Holman, D.J., Unsworth, K.L., Wall, T.D., Waterson, P.E. and Harrington, E. (2000), "Shopfloor innovation: facilitating the suggestion and implementation of ideas", Journal of Occupational and Organizational Psychology, Vol. 73 No. 3, pp. 265-285, doi: 10.1348/ 096317900167029.

Battistelli, A., Montani, F. and Odoardi, C. (2013), "The impact of feedback from job and task autonomy in the relationship between dispositional resistance to change and innovative work behaviour", European Journal of Work and Organizational Psychology, Vol. 22 No. 1, pp. 26-41, doi: 10.1080/1359432x.2011.616653.

Battistelli, A., Odoardi, C., Cangialosi, N., Di Napoli, G. and Piccione, L. (2021), "The role of image expectations in linking organizational climate and innovative work behaviour", European Journal of Innovation Management, Advance online publication. doi: 10.1108/EJIM-01-2021-0044.

Beynon, M.J., Jones, P. and Pickernell, D. (2016), "Country-based comparison analysis using fsQCA investigating entrepreneurial attitudes and activity", Journal of Business Research, Vol. 69 No. 4, pp. 1271-1276, doi: 10.1016/j.jbusres.2015.10.091.

Birnbaum, P.H., Farh, J.L. and Wong, G.Y. (1986), "The job characteristics model in Hong Kong”, Journal of Applied Psychology, Vol. 71 No. 4, pp. 598-605, doi: 10.1037/0021-9010.71.4.598.

Brislin, R.W. (1980), "Cross-cultural research methods: strategies, problems, applications", in Altman, I., Rapoport, A. and Wohlwill, J.F. (Eds), Human Behavior and Environment, Plenum Press, New York, pp. 47-82. doi: 10.1007/978-1-4899-0451-5_3.

Cangialosi, N., Odoardi, C. and Battistelli, A. (2020a), "A three-way interaction model of innovative behavior, task-related learning, and job characteristics", Performance Improvement Quarterly, Vol. 33 No. 2, pp. 153-172, doi: 10.1002/piq.21322.

Cangialosi, N., Odoardi, C. and Battistelli, A. (2020b), "Learning climate and innovative work behavior, the mediating role of the learning potential of the workplace", Vocations and Learning, Vol. 13 No. 2, pp. 1-18, doi: 10.1007/s12186-019-09235-y.

Cangialosi, N., Odoardi, C., Battistelli, A. and Baldaccini, A. (2021), "The social side of innovation: when and why advice network centrality promotes innovative work behaviours", Creativity and Innovation Management, Vol. 30 No. 2, pp. 336-347, doi: 10.1111/caim.12434.

Černe, M., Hernaus, T., Dysvik, A. and Škerlavaj, M. (2017), "The role of multilevel synergistic interplay among team mastery climate, knowledge hiding, and job characteristics in stimulating innovative work behavior”, Human Resource Management Journal, Vol. 27 No. 2, pp. 281-299, doi: 10.1111/1748-8583.12132.

Chang, S., Gong, Y. and Shum, C. (2011), "Promoting innovation in hospitality companies through human resource management practices", International Journal of Hospitality Management, Vol. 30 No. 4, pp. 812-818, doi: 10.1016/j.ijhm.2011.01.001.

Chen, C.J., Shih, H.A. and Yeh, Y.C. (2011), "Individual initiative, skill variety, and creativity: the moderating role of knowledge specificity and creative resources", The International Journal of Human Resource Management, Vol. 22 No. 17, pp. 3447-3461, doi: 10.1080/09585192.2011.599940.

Coelho, F. and Augusto, M. (2010), "Job characteristics and the creativity of frontline service employees", Journal of Service Research, Vol. 13 No. 4, pp. 426-438, doi: 10.1177/ 1094670510369379.

Dahms, S. and Kingkaew, S. (2019), “A configurational perspective on subsidiary top management team national diversity and performance”, Personnel Review, Vol. 48 No. 6, pp. 1507-1529, doi: 10.1108/PR-10-2018-0389.

Daniels, K., Gedikli, C., Watson, D., Semkina, A. and Vaughn, O. (2017), "Job design, employment practices and well-being: a systematic review of intervention studies", Ergonomics, Vol. 60 No. 9, pp. 1177-1196, doi: 10.1080/00140139.2017.1303085. 
PR

52,1

De Jong, J.P. and Kemp, R. (2003), “Determinants of co-workers' innovative behaviour: an investigation into knowledge intensive services", International Journal of Innovation Management, Vol. 7 No. 2, pp. 189-212, doi: 10.1142/s1363919603000787.

De Treville, S. and Antonakis, J. (2006), "Could lean production job design be intrinsically motivating? Contextual, configurational, and levels-of-analysis issues", Journal of Operations Management, Vol. 24 No. 2, pp. 99-123, doi: 10.1016/j.jom.2005.04.001.

Deegahawature, M.M.D.R. (2014), "Managers' inclination towards open innovation: effect of job characteristics", European Journal of Business and Management, Vol. 6 No. 1, pp. 8-16.

Dorenbosch, L., Engen, M.L.V. and Verhagen, M. (2005), "On-the-job innovation: the impact of job design and human resource management through production ownership", Creativity and Innovation Management, Vol. 14 No. 2, pp. 129-141, doi: 10.1111/j.1476-8691.2005.00333.x.

Farivar, F., Coffey, J. and Cameron, R. (2019), "International graduates and the change of initial career mobility intentions", Personnel Review, Vol. 48 No. 4, pp. 1061-1078, doi: 10.1108/PR-012017-0007.

Fiss, P.C. (2011), "Building better causal theories: a fuzzy set approach to typologies in organization research", Academy of Management Journal, Vol. 54 No. 2, pp. 393-420, doi: 10.5465/amj.2011. 60263120.

Fornell, C. and Larcker, D.F. (1981), "Structural equation models with unobservable variables and measurement error: algebra and statistics", Journal of Marketing Research, Vol. 18 No. 3, p. 382, doi: $10.2307 / 3150980$.

Frese, M., Garst, H. and Fay, D. (2007), "Making things happen: reciprocal relationships between work characteristics and personal initiative in a four-wave longitudinal structural equation model", Journal of Applied Psychology, Vol. 92 No. 4, pp. 1084-1102, doi: 10.1037/0021-9010.92.4.1084.

Gong, Y., Huang, J.C. and Farh, J.L. (2009), "Employee learning orientation, transformational leadership, and employee creativity: the mediating role of employee creative self-efficacy", Academy of Management Journal, Vol. 52 No. 4, pp. 765-778, doi: 10.5465/amj.2009.43670890.

Grant, A.M., Fried, Y. and Juillerat, T. (2011), "Work matters: job design in classic and contemporary perspectives", in APA Handbook of Industrial and Organizational Psychology, Building and Developing the Organization, Vol. 1, pp. 417-453. doi: 10.1037/12169-013.

Greckhamer, T., Furnari, S., Fiss, P.C. and Aguilera, R.V. (2018), "Studying configurations with qualitative comparative analysis: best practices in strategy and organization research", Strategic Organization, Vol. 16 No. 4, pp. 482-495, doi: 10.1177/1476127018786487.

Gupta, V. (2020), "Relationships between leadership, motivation and employee-level innovation: evidence from India”, Personnel Review, Vol. 49 No. 7, pp. 1363-1379, doi: 10.1108/PR-112019-0595.

Hackman, J.R. and Oldham, G.R. (1975), "Development of the job diagnostic survey", Journal of Applied Psychology, Vol. 60 No. 2, pp. 159-170, doi: 10.1037/h0076546.

Hartmann, A. (2006), "The role of organizational culture in motivating innovative behaviour in construction firms", Construction Innovation, Vol. 6 No. 3, pp. 159-172, doi: 10.1108/ 14714170610710712.

Hernaus, T. (2016), "Job design at the crossroads: from 'creative' jobs to 'innovative' jobs", in Škerlavaj, M., Cerne, M., Dysvik, A. and Carlsen, A. (Eds), Capitalizing on Creativity at Work: Fostering the Implementation of Creative Ideas in Organizations, Edward Elgar, Cheltenham, pp. 17-28. doi: 10.4337/9781783476503.

Hinton, M. and Biderman, M. (1995), "Empirically derived job characteristics measures and the motivating potential score", Journal of Business and Psychology, Vol. 9 No. 4, pp. 355-364, doi: 10.1007/bf02230975.

Humphrey, S.E., Nahrgang, J.D. and Morgeson, F.P. (2007), "Integrating motivational, social, and contextual work design features: a meta-analytic summary and theoretical extension of the 
work design literature", Journal of Applied Psychology, Vol. 92 No. 5, pp. 1332-1356, doi: 10.1037/ 0021-9010.92.5.1332.

Janssen, O. (2000), "Job demands, perceptions of effort-reward fairness and innovative work behaviour", Journal of Occupational and Organizational Psychology, Vol. 73 No. 3, pp. 287-302, doi: 10.1348/096317900167038.

Kmieciak, R. (2020), "Critical reflection and innovative work behavior: the mediating role of individual unlearning”, Personnel Review, Vol. 50 No. 2, pp. 439-459, doi: 10.1108/PR-10-2018-0406.

Lee, M.H. and Jeon, K.S. (2020), "Relationship between autonomy and task significance and creative behavior in military: the mediating effect of self-efficacy", The Journal of the Korea Contents Association, Vol. 20 No. 10, pp. 580-592, doi: 10.5392/JKCA.2020.20.10.580.

Lee, M.T. and Raschke, R.L. (2016), "Understanding employee motivation and organizational performance: arguments for a set-theoretic approach", Journal of Innovation and Knowledge, Vol. 1 No. 3, pp. 162-169, doi: 10.1016/j.jik.2016.01.004.

Li, M. and Hsu, C.H. (2016), "A review of employee innovative behavior in services", International Journal of Contemporary Hospitality Management, Vol. 28 No. 12, pp. 2820-2841, doi: 10.1108/ IJCHM-04-2015-0214.

Lo, F.Y., Wang, Y. and Zhan, W. (2019), "Does TMT cultural diversity contribute to firm performance and do socialisation and tenure matter? A test of two competing perspectives", Personnel Review, Vol. 49 No. 1, pp. 324-348, doi: 10.1108/PR-11-2018-0468.

Luoh, H.-F., Tsaur, S.-H. and Tang, Y.-Y. (2014), "Empowering employees: job standardization and innovative behavior", International Journal of Contemporary Hospitality Management, Vol. 26 No. 7, pp. 1100-1117, doi: 10.1108/ijchm-03-2013-0153.

Matthew, O.T., Chigozie, U.B. and Benjamin, C.O. (2014), "Perception of job characteristics and age as determinants of employee creativity", European Journal of Business and Management, Vol. 6 No. 12, pp. 119-123.

Meuer, J. and Fiss, P.C. (2020), "Qualitative comparative analysis in business and management research", in Oxford Research Encyclopedia of Business and Management. doi: 10.1093/acrefore/ 9780190224851.013.229.

Meyer, A.D., Tsui, A.S. and Hinings, C.R. (1993), "Configurational approaches to organizational analysis", Academy of Management Journal, Vol. 36 No. 6, pp. 1175-1195, doi: 10.5465/256809.

Morgeson, F.P. and Humphrey, S.E. (2006), "The work design questionnaire (WDQ): developing and validating a comprehensive measure for assessing job design and the nature of work", Journal of Applied Psychology, Vol. 91 No. 6, pp. 1321-1339, doi: 10.1037/0021-9010.91.6.1321.

Ohly, S. and Fritz, C. (2010), "Work characteristics, challenge appraisal, creativity, and proactive behavior: a multi-level study", Journal of Organizational Behavior, Vol. 31 No. 4, pp. 543-565, doi: 10.1002/job.633.

Oldham, G.R. and Cummings, A. (1996), "Employee creativity: personal and contextual factors at work", Academy of Management Journal, Vol. 39 No. 3, pp. 607-634, doi: 10.5465/256657.

Oldham, G.R. and Fried, Y. (2016), "Job design research and theory: past, present and future", Organizational Behavior and Human Decision Processes, Vol. 136, pp. 20-35, doi: 10.1016/j. obhdp.2016.05.002.

Ordanini, A., Parasuraman, A. and Rubera, G. (2014), "When the recipe is more important than the ingredients: a qualitative comparative analysis (QCA) of service innovation configurations", Journal of Service Research, Vol. 17 No. 2, pp. 134-149, doi: 10.1177/1094670513513337.

Paas, F. and van Merriënboer, J.J. (2020), "Cognitive-load theory: methods to manage working memory load in the learning of complex tasks", Current Directions in Psychological Science, Vol. 29 No. 4, pp. 394-398, doi: 10.1177/0963721420922183.

Pappas, I.O., Kourouthanassis, P.E., Giannakos, M.N. and Lekakos, G. (2017), “The interplay of online shopping motivations and experiential factors on personalized e-commerce: a complexity theory approach", Telematics and Informatics, Vol. 34 No. 5, pp. 730-742, doi: 10.1016/j.tele.2016.08.021. 
PR

52,1

\section{8}

Park, T.S. and Kim, S.W. (2016), "A study on awareness of job characteristics and job satisfaction of landscape architect public officials in Korea", Journal of the Korean Institute of Landscape Architecture, Vol. 44 No. 6, pp. 148-161, doi: 10.9715/kila.2016.44.6.148.

Parker, S.K. (2014), "Beyond motivation: job and work design for development, health, ambidexterity, and more", Annual Review of Psychology, Vol. 65, doi: 10.1146/annurev-psych-010213-115208.

Parker, S.K., Morgeson, F.P. and Johns, G. (2017), "One hundred years of work design research: looking back and looking forward”, Journal of Applied Psychology, Vol. 102 No. 3, pp. 403-420, doi: 10.1037/ap10000106.

Parker, S.K. and Ohly, S. (2008), "Designing motivating jobs: an expanded framework for linking work characteristics and motivation", in Kanfer, R., Chen, G. and Pritchard, R.D. (Eds), The Organizational Frontiers Series: Vol. 27. Work Motivation: Past, Present, and Future, Routledge/ Taylor and Francis Group, pp. 233-284.

Parker, S.K., Ward, M.K. and Fisher, G. (2021), "Can high-quality jobs help adults learn new tricks? A multi-disciplinary review of work design for cognition", Academy of Management Annals, Vol. 15 No. 2, pp. 406-454, doi: 10.5465/annals.2019.0057.

Podsakoff, P.M., MacKenzie, S.B. and Podsakoff, N.P. (2012), "Sources of method bias in social science research and recommendations on how to control it", Annual Review of Psychology, Vol. 63, pp. 539-569, doi: 10.1146/annurev-psych-120710-100452.

Potočnik, K. and Anderson, N. (2016), "A constructively critical review of change and innovationrelated concepts: towards conceptual and operational clarity", European Journal of Work and Organizational Psychology, Vol. 25 No. 4, pp. 481-494, doi: 10.4324/9780203732427-2.

Ragin, C.C. (2006), "Set relations in social research: evaluating their consistency and coverage", Political Analysis, Vol. 14 No. 3, pp. 291-310, doi: 10.1093/pan/mpj019.

Ragin, C.C. (2008), Redesigning Social Inquiry, University of Chicago Press, Chicago. doi: 10.7208/ 9780226702797.

Salancik, G.R. and Pfeffer, J. (1978), "A social information processing approach to job attitudes and task design”, Administrative Science Quarterly, Vol. 22 No. 3, pp. 224-253, doi: 10.2307/2392563.

Schneider, C.Q. and Wagemann, C. (2010), "Standards of good practice in qualitative comparative analysis (QCA) and fuzzy-sets", Comparative Sociology, Vol. 9 No. 3, pp. 397-418, doi: 10.1163/ $156913210 X 12493538729793$.

Shalley, C.E., Gilson, L.L. and Blum, T.C. (2009), "Interactive effects of growth need strength, work context, and job complexity on self-reported creative performance", Academy of Management Journal, Vol. 52 No. 3, pp. 489-505, doi: 10.5465/amj.2009.41330806.

Skaaning, S.E. (2011), “Assessing the robustness of crisp-set and fuzzy-set QCA results”, Sociological Methods and Research, Vol. 40 No. 2, pp. 391-408, doi: 10.1177/0049124111404818.

Slåtten, T. and Mehmetoglu, M. (2011), "What are the drivers for innovative behavior in frontline jobs? A study of the hospitality industry in Norway", Journal of Human Resources in Hospitality and Tourism, Vol. 10 No. 3, pp. 254-272, doi: 10.1080/15332845.2011.555732.

Talat, A. and Riaz, Z. (2020), "An integrated model of team resilience: exploring the roles of team sensemaking, team bricolage and task interdependence", Personnel Review, Vol. 49 No. 9, pp. 2007-2033, doi: 10.1108/PR-01-2018-0029.

Wang, A.C. and Cheng, B.S. (2010), "When does benevolent leadership lead to creativity? The moderating role of creative role identity and job autonomy", Journal of Organizational Behavior, Vol. 31 No. 1, pp. 106-121, doi: 10.1002/job.634.

Whittington, J.L., Goodwin, V.L. and Murray, B. (2004), "Transformational leadership, goal difficulty, and job design: independent and interactive effects on employee outcomes", The Leadership Quarterly, Vol. 15 No. 5, pp. 593-606, doi: 10.1016/j.leaqua.2004.07.001.

Woodside, A.G. (2014), "Embrace perform model: complexity theory, contrarian case analysis, and multiple realities", Journal of Business Research, Vol. 67 No. 12, pp. 2495-2503, doi: 10.1016/j. jbusres.2014.07.006. 
Yang, H.C. and Cho, H.Y. (2015), "Effects of individuals, leader relationships, and groups on innovative work behaviors", The Journal of Industrial Distribution and Business, Vol. 6 No. 3, pp. 19-25, doi: 10.13106/ijidb.2015.vol6.no3.19.

Zhang, L. and Farndale, E. (2021), "Workforce age profile effects on job resources, work engagement and organizational citizenship behavior”, Personnel Review, Advance online publication. doi: 10 . 1108/PR-02-2020-0095.

Zhang, X. and Bartol, K.M. (2010), "Linking empowering leadership and employee creativity: the influence of psychological empowerment, intrinsic motivation, and creative process engagement", Academy of Management Journal, Vol. 53 No. 1, pp. 107-128, doi: 10.5465/amj. 2010.48037118.

Zhang, W., Xu, F. and Sun, B. (2020), "Openness to experience, job characteristics, and employee creativity: an interactionist perspective", Social Behavior and Personality: An International Journal, Vol. 48 No. 4, pp. 1-12, doi: 10.2224/sbp.9047.

\section{Further reading}

Chen, L., Li, M., Wu, Y.J. and Chen, C. (2020), "The voicer's reactions to voice: an examination of employee voice on perceived organizational status and subsequent innovative behavior in the workplace”, Personnel Review, Vol. 50 No. 4, pp. 1073-1092, doi: 10.1108/PR-07-2019-0399.

Tho, N.D. and Trang, N.T.M. (2015), "Can knowledge be transferred from business schools to business organizations through in-service training students? SEM and fSQCA findings", Journal of Business Research, Vol. 68 No. 6, pp. 1332-1340, doi: 10.1016/j.jbusres.2014.12.003.

\section{Corresponding author}

Nicola Cangialosi can be contacted at: nicola.cangialosi@unifi.it

For instructions on how to order reprints of this article, please visit our website: 